\title{
Skin diseases in patients with primary psychiatric conditions admitted in Psychiatry ward
}

\author{
Pradhan Manish${ }^{1}$, Kaul Bijaya ${ }^{2}$, Rai Dipa ${ }^{1}$
}

1. Department of Dermatology, Nobel Medical College, Biratnagar Nepal 2. Department of Psychiatry, Nobel Medical College, Biratnagar Nepal

E-mail *Corresponding author: drmanishpradhan1@gmail.com

\begin{abstract}
Introduction: The relation between psychiatric disorder and dermatological illness is well known but limited studies have been conducted to show significant association. This study was carried To find out the prevalence and frequency of dermatological illness in primary psychiatric patient.

Material And Method: One hundred and fifty patients with primary psychiatric disease admitted in Nobel Medical College and Teaching Hospital from October 2017 to October 2018 with same number of age, sex and social class matched controls were studied. A detailed dermatological and psychiatric evaluation was done in all cases and controls.

Results: The mean age for primary psychiatric illness was $30.94 \pm 14.28$ years. Dermatological conditions found in $82.67 \%$ of primary psychiatric condition was higher than that of controls $(43.3 \%)$. The most common psychiatric condition was Schizophrenia (25.3\%) followed by Depression (28\%). A significantly higher incidence of infective dermatoses was seen in $65(43.4 \%)$ of cases as compared to control $46(30.6 \%)$ [ $p$ value $=0.023$ ] in which dermatophytic infections was profundly found in about 22 (14.7\%) patients. Parasitic infestation was seen in $20 \%$ of psychiatric patients, of these scabies was present in 20 (13.3\%) and pediculosis in 10 (6.7\%) cases. Among noninfective skin disorder, high incidence of eczema 17 (11.3\%) and generalized pruritus 15 (10\%) was seen.

Conclusion: There is a definite association of skin disease and primary psychiatric illness of which infective skin diseases are significantly higher in psychiatric patient.
\end{abstract}

Keywords: Skin Disease, Psychiatric illness, Nepal

\section{INTRODUCTION}

It is essential to consider the possibilities of the interrelation between dermatological disorders and psychiatric conditions. ${ }^{[1]}$ Stress, anxiety and depression has been found to contribute to the severity of pre- existing dermatoses like acne, psoriasis or atopic dermatitis or they can lead to the development of so called psycho-cutaneous changes which can be challenging and frustrating to both clinicians as well as patients. ${ }^{[2]}$

Psychiatric disorders are any pattern of psychological or behavioral symptoms that cause individual significant distress, impairing their ability to function in life and/or significantly increase their risk of death, pain, disability or loss of freedom. ${ }^{[1]}$

The ready accessibility of the skin, together with an appreciation of the variety of cutaneous psycho-physiologic emotional responses-to wit, sweating, blushing, pallor-made it an important vehicle for study in the early days of psychosomatic research. ${ }^{[3]}$ The influence of psychological factors on skin disease is fairly common, although few studies and debates are done in this regard. ${ }^{[2]}$ 
A patient may use skin to communicate emotional distress. Psychiatric patients often have a defensive need to deny their psychopathology and seek dermatological care for their prominent cutaneous symptoms. ${ }^{[4]}$ It has been estimated that effective management of at least one third of the patients attending the dermatology department depends, to some extent, upon the recognition of emotional factors. [5]

There are few published datas on the frequency of dermatoses in such patients, so this study was aimed to document the incidence of cutaneous disorders in patients with primary psychiatric conditions.

\section{MATERIAL AND METHOD}

A hospital based, case control study was conducted over a period of one year; from October 2017 to October 2018 on a total of 150 patients admitted under Department of Psychiatry, Nobel Medical College, Biratnagar-4, Nepal and; age and gender matched controls of the same number.

Inclusion criteria for psychiatric patients with primary psychiatric disorders:

- Those patients admitted in Psychiatry department

Exclusion criteria for patients with psychiatric disorders:

- Patient with secondary psychiatric disorders.

- Patients with any systemic disorders associated with these chronic diseases, such as diabetes mellitus, liver and renal diseases in order to exclude cutaneous manifestations of them.

- Patients on long-term bed rest.

Selection of subjects free from psychiatric disorders:

Individuals not suffering from psychiatric disorders were recruited from those accompanying the patients and other individuals accompanying patients of other outpatient clinics and wards. After explaining the purpose of the study to the psychiatric patients or their relatives and psychiatric disease-free individuals, informed written consents were taken.

Inclusion criteria for controls are:
- Individuals free from psychiatric disorders according to psychiatric consultation.

- Age, sex and social class matched to patient's group.

Exclusion criteria for controls are:

- Individuals with any systemic disease, such as diabetes mellitus, liver and renal diseases.

- Relatives of psychiatric patients.

All participants were subjected to

1. Psychiatric consultation by a psychiatrist using The Diagnostic and Statistical Manual of Mental Disorders (DMS IV) Criteria that describes the symptoms for all mental disorders and the criteria that must be met to receive a diagnosis of each disorder or exclude psychiatric disease in healthy controls.

2. A specially designed questionnaire including items about sociodemographic data: age, sex, origin, residence, marital status, smoking and special habits, education, occupation and social class.

3. Dermatological examination: Highly qualified dermatologists carried out a complete dermatological examination, and special investigations were done when needed (e.g. scraping for fungus, biopsy.).

4. General clinical examinations and investigations to exclude systemic diseases were done (complete blood count, liver and renal function tests, fasting and post-prandial blood glucose, etc.)

Then, the data collected and analysed by SPSS software (version 21). The statistical analysis of the data was done by using chi-square test and the test was referenced for $\mathrm{p}$-values. The $\mathrm{p}$ values of less than 0.05 was taken to be significant.

\section{RESULT}

Out of 150 patients enrolled in the study as case, $69(46 \%)$ were male patients and $81(54 \%)$ were female. The mean age of the patients was $30.94 \pm$ 14.28; the youngest being 13 and the oldest being 82 . Dermatological disorder was found in $124(82.67 \%)$ cases. Similarly, out of 150 controls, $65(43.3 \%)$ male and 85 (56.7\%) female 
participated; the mean age of the controls being $32.06 \pm 14.94$. Among them; skin disorders were found in $65(43.3 \%)$.

The most common psychiatric conditions found in our study were Schizophrenia 38 (25.3\%); followed by depression 28 (18.7\%); anxiety disorder 26 (17.3\%). Alcohol dependence syndrome was found in 16 patients $(10.7 \%)$ and similar presentation seen in mood disorder/ bipolar affective disorder $16(10.7 \%)$. Similarly, conversion disorder seen in $14(9.3 \%)$ patients; obsessive compulsive disorder in $9(6 \%)$ and substance abuse in $3(2 \%)$ patients. Detail Of the result is shown in table 1 .

Table 1: Distribution of common psychiatric disorders in male/female patients enrolled in our study

\begin{tabular}{|c|c|c|c|}
\hline $\begin{array}{l}\text { Psychiatric } \\
\text { disorders }\end{array}$ & $\begin{array}{l}\text { Male } \\
\text { n(\%) }\end{array}$ & $\begin{array}{c}\text { Female } \\
\mathrm{n}(\%)\end{array}$ & $\begin{array}{l}\text { Total } \\
\text { n(\%) }\end{array}$ \\
\hline Schizophrenia & $\begin{array}{c}22 \\
(14.6 \%)\end{array}$ & $\begin{array}{c}16 \\
(10.6 \%)\end{array}$ & $\begin{array}{c}38 \\
(25.3 \%)\end{array}$ \\
\hline Depression & $\begin{array}{c}12 \\
(8.0 \%) \\
\end{array}$ & $\begin{array}{c}16 \\
(10.6 \%)\end{array}$ & $\begin{array}{c}28 \\
(18.7 \%) \\
\end{array}$ \\
\hline $\begin{array}{l}\text { Generalized } \\
\text { anxiety } \\
\text { disorder }\end{array}$ & $\begin{array}{c}7 \\
(4.6 \%)\end{array}$ & $\begin{array}{c}19 \\
(12.6 \%)\end{array}$ & $\begin{array}{c}26 \\
(17.3 \%)\end{array}$ \\
\hline $\begin{array}{l}\text { Bipolar } \\
\text { affective } \\
\text { disorder }\end{array}$ & $\begin{array}{c}9 \\
(6.0 \%)\end{array}$ & $\begin{array}{c}7 \\
(4.6 \%)\end{array}$ & $\begin{array}{c}16 \\
(10.7 \%)\end{array}$ \\
\hline $\begin{array}{c}\text { Alcohol } \\
\text { dependence } \\
\text { syndrome }\end{array}$ & $\begin{array}{c}12 \\
(8.0 \%)\end{array}$ & $\begin{array}{c}4 \\
(2.6 \%)\end{array}$ & $\begin{array}{c}16 \\
(10.7 \%)\end{array}$ \\
\hline $\begin{array}{c}\text { Conversion } \\
\text { disorder }\end{array}$ & $\begin{array}{c}2 \\
(1.3 \%) \\
\end{array}$ & $\begin{array}{c}12 \\
(8.0 \%)\end{array}$ & $\begin{array}{c}14 \\
(9.3 \%)\end{array}$ \\
\hline $\begin{array}{l}\text { Obsessive } \\
\text { compulsive } \\
\text { disorder }\end{array}$ & $\begin{array}{c}3 \\
(2.0 \%)\end{array}$ & $\begin{array}{c}6 \\
(4.0 \%)\end{array}$ & $\begin{array}{c}9 \\
(6 \%)\end{array}$ \\
\hline $\begin{array}{c}\text { Substance } \\
\text { abuse }\end{array}$ & $\begin{array}{c}2 \\
(1.3 \%)\end{array}$ & $\begin{array}{c}1 \\
(0.6 \%) \\
\end{array}$ & $\begin{array}{c}3 \\
(2 \%) \\
\end{array}$ \\
\hline Total & $\begin{array}{c}69 \\
(45.8 \%)\end{array}$ & $\begin{array}{c}81 \\
(53.6 \%)\end{array}$ & $\begin{array}{c}150 \\
(100 \%)\end{array}$ \\
\hline
\end{tabular}

A high incidence of infective dermatoses was seen in $43.4 \%$ of cases $(n=65)$ in which dermatophytic infections was profoundly found in about $22(14.7 \%)$ patients; followed by scabies $20(13.3 \%)$ and other diseases presented in following table 2. Among the fungal infections, tinea corporis, onychomycosis (2\%) and pityriasis versicolor $(6 \%)$ were mostly found. Similarly, other non-infective dermatoses was also found which is illustrated in table 2 .

Table 2: Distribution of common dermatologic disorders in the study group $(\mathrm{n}=150)$

\begin{tabular}{|c|c|c|c|}
\hline Skin disorders & Male & Female & Total \\
\hline \multicolumn{4}{|l|}{$\begin{array}{l}\text { Infective } \\
\text { Dermatoses: }\end{array}$} \\
\hline Scabies & $9(13 \%)$ & $\begin{array}{l}11 \\
(13.6 \%)\end{array}$ & $26.6 \%$ \\
\hline Tinea & $\begin{array}{l}11 \\
(15.9 \%)\end{array}$ & $\begin{array}{l}11 \\
(13.6 \%)\end{array}$ & $29.5 \%$ \\
\hline $\begin{array}{l}\text { Pityriasis } \\
\text { versicolor }\end{array}$ & $5(7.2 \%)$ & $4(4.9 \%)$ & $12.1 \%$ \\
\hline Pediculosis & $5(7.2 \%)$ & $5(6.2 \%)$ & $13.4 \%$ \\
\hline Pyoderma & $1(1.4 \%)$ & - & $1.4 \%$ \\
\hline Onychomycosis & $1(1.4 \%)$ & $2(2.5 \%)$ & $3.9 \%$ \\
\hline \multicolumn{4}{|l|}{$\begin{array}{l}\text { Non-infective } \\
\text { Dermatoses: }\end{array}$} \\
\hline Eczema & $5(7.2 \%)$ & $\begin{array}{l}12 \\
(14.8 \%) \\
\end{array}$ & $22 \%$ \\
\hline Pruritus & $4(5.8 \%)$ & $\begin{array}{l}11 \\
(13.6 \%) \\
\end{array}$ & $19.4 \%$ \\
\hline Xerosis & $\begin{array}{l}10 \\
(14.5 \%)\end{array}$ & $1(1.2 \%)$ & $15.7 \%$ \\
\hline Acne & $2(2.9 \%)$ & $6(7.4 \%)$ & $10.3 \%$ \\
\hline Melasma & $2(2.9 \%)$ & $2(2.5 \%)$ & $5.4 \%$ \\
\hline \multicolumn{4}{|c|}{ Psychocutaneous disorders: } \\
\hline $\begin{array}{l}\text { Neurotic } \\
\text { excoriations }\end{array}$ & $2(2.9 \%)$ & $2(2.5 \%)$ & $5.4 \%$ \\
\hline None & $\begin{array}{l}12 \\
(17.4 \%)\end{array}$ & $\begin{array}{l}14 \\
(17.3 \%)\end{array}$ & $34.7 \%$ \\
\hline
\end{tabular}

Parasitic infestations were seen in about $20 \%$ of the study group. Of these, scabies was present in $20(13.3 \%)$ and pediculosis in $10(6.7 \%)$ patients. Among the non-infective skin disorders seen in our study group; a high incidence of eczema in $17(11.3 \%)$ and generalized pruritus $15(10 \%)$ are seen; followed by xerosis $11(7.3 \%)$, acne 8 $(5.3 \%)$, melasma $4(2.7 \%)$.

Similarly; the dermatological diseases seen in control study group is illustrated on the following table 3 . 
Table 3 : Distribution of common dermatologic disorders in the control study group $(n=150)$

\begin{tabular}{|l|l|}
\hline Skin disorders & Total \\
\hline Infectious diseases: & $10(6.67 \%)$ \\
\hline Scabies & $22(14.6 \%)$ \\
\hline Tinea & $4(2.67 \%)$ \\
\hline Pityriasis versicolor & $4(2.67 \%)$ \\
\hline Pediculosis & $4(2.67 \%)$ \\
\hline Pyoderma & $2(1.33 \%)$ \\
\hline Onychomycosis & $11(7.3 \%)$ \\
\hline Non infectious disease: & $2(1.33 \%)$ \\
\hline Eczema & $1(0.7 \%)$ \\
\hline Pruritus & $4(2.67 \%)$ \\
\hline Xerosis & $1(0.7 \%)$ \\
\hline Acne & $85(56.67 \%)$ \\
\hline Melasma &
\end{tabular}

The prevalence of major skin diseases in some major primary psychiatric diseases are illustrated in table 4 .

Table 4 : Major skin disorders occurring in major psychiatric diseases
In the same way, the number of psychiatric patients with infectious skin diseases was 65 patients $(43.4 \%$ of all psychiatric patients and $52.4 \%$ of psychiatric patients with skin diseases). The number of non-psychiatric controls with infectious skin diseases was 46 patients $(30.6 \%$ of all non-psychiatric patients and $70.6 \%$ of nonpsychiatric patients with skin diseases). The infectious skin diseases are significantly higher $(\mathrm{P}<0.023)$ in patients with primary psychiatric disorders than from patients free from psychiatric disorders (Table 5).

Table 5: Infectious and non-infectious skin diseases among dermatological patients of both studied groups

\begin{tabular}{|l|l|c|l|c|}
\hline $\begin{array}{l}\text { Dermatological } \\
\text { Patients }\end{array}$ & \multicolumn{2}{|l|}{$\begin{array}{l}\text { Cases } \\
\text { (patients with } \\
\text { psychiatric } \\
\text { disease) n=124 }\end{array}$} & \multicolumn{2}{|l|}{$\begin{array}{l}\text { Controls (patients } \\
\text { free of psychiatric } \\
\text { disease) n=150 }\end{array}$} \\
\hline Skin disease & No. & $\%$ & No & $\%$ \\
\hline Infectious & 65 & 43.4 & 46 & 30.6 \\
\hline Non infectious & 59 & 39.3 & 19 & 12.7 \\
\hline
\end{tabular}

\begin{tabular}{|l|l|l|l|l|l|l|}
\hline Diseases & Schizophrenia & Depression & $\begin{array}{l}\text { Anxiety } \\
\text { disorders }\end{array}$ & OCD & BPAD \\
\hline Infectious diseases: & $5(13.2 \%)$ & $10(35.7 \%)$ & - & - & $5(31.3 \%)$ \\
\hline Scabies & $15(39.5 \%)$ & $2(7.1 \%)$ & - & - & $5(31.3 \%)$ \\
\hline Tinea infections & $5(13.2 \%)$ & $5(17.9 \%)$ & - & - & - \\
\hline Pediculosis & $5(13.2 \%)$ & $4(14.3 \%)$ & - & - & - \\
\hline P. versicolor & $1(2.6 \%)$ & $2(7.1 \%)$ & - & - & - \\
\hline Onychomycosis & - & $1(3.6 \%)$ & - & - & - \\
\hline Pyoderma & - & $1(3.6 \%)$ & - & $2(22.2 \%)$ & $1(6.3 \%)$ \\
\hline Noninfectious diseases: & $1(2.6 \%)$ & - & $12(46.2 \%)$ & $3(33.3 \%)$ & - \\
\hline Xerosis & - & - & $4(15.4 \%)$ & $2(22 \%)$ & - \\
\hline Eczema & - & $2(7.1 \%)$ & $4(15.4 \%)$ & - & - \\
\hline Pruritus & - & - & $2(7.1 \%)$ & - & - \\
\hline Acne & - & $1(3.6 \%)$ & $4(15.4 \%)$ & $2(22 \%)$ & $5(31.3 \%)$ \\
\hline Psychocutaneous & disorder: & $6(15.8 \%)$ & & & \\
\hline $\begin{array}{l}\text { Neurotic } \\
\text { excoriations }\end{array}$ & None & & -5 & & - \\
\hline
\end{tabular}




\section{DISCUSSION:}

In the present study dermatological disease were seen significantly common in patient with primary psychiatric condition $(82.67 \%)$ as compared to non-psychiatric controls (43.3\%). This is in agreement with the study conducted by Mookhoek et al. ${ }^{6}$ who found skin diseases were more common in patient with admitted psychiatric condition and Moftah et. al. ${ }^{1}$ who found it to be $71.7 \%$ in a study conducted in out patient basis. Current study was conducted by excluding the patient with systemic diseases like diabetes, kidney, liver and thyroid disorder which can increases the risk of skin diseases.

Infectious dermaotses were more common in psychiatric patients $(43.4 \%)$ compare to nonpsychiatric controls (30.6\%) that was significantly higher in psychiatric patients. This result correlate with study done by Kuruvila et al. ${ }^{4}$ who conducted the study in 300 cases and 300 controls and found skin infection in psychiatric patient to be significantly higher $(68.7 \%$ vs. $56.6 \%)$. Segerstorm and Miller 7 reported that psychiatric condition and chronic stress is consistently associated with decreased natural killer cell cytotoxicity and decreased lymphocyte proliferation leading to increased susceptibility to skin infection. The most common infectious disease in our study was fungal infection followed by parasitic infestation. This was in contrast with study done by chosidow ${ }^{8}$ and Mooftah et al. ${ }^{1}$ who found that prevalence of parasitic infestation, scabies and pediculosis, was higher in psychiatric patient than fungal infection. The higher prevalence of fungal infection may be attributed to the hot and humid climate of the place where study was conducted where the prevalence of fungal infection is high compare to parasitic infestation. Most of the infective dermatosis were seen in patients with schizophrenia, then depression and mood disorder but not seen in patient with obsessive compulsive disorder and anxiety.

Negligence of hygiene may be the cause for higher prevalence of skin infection in schizophrenia. ${ }^{9}$ patient with schizophrenia were unable to carry out their normal daily activities or unable to work, in addition to a poor level of personal awareness regarding personal hygiene and overall cleanliness. ${ }^{1}$ Depression is one of the mood disorder that is characterized by loss of interest, lack of energy, low self esteem and difficult ability in experiencing pleasure, social problems and irritability which interfere with physical activity leading to lack of personal care which in turn increases the susceptibility to infection. ${ }^{10}$ In patients with obsessive compulsive disorder patients' compulsion to cleanliness like irresistible urge to wash (particularly hand) or clean, the patients frequently wash the hands and clean themselves, and thus make them less susceptible to infections. ${ }^{1}$

Regarding non-infectious dermatosis the prevalence did not differ from control group, but in patient with primary psychiatric disease it was more common in patient with Obsessive compulsive disorder and anxiety disorder than with other.

Psychocutaneous disorder, which is thought to be primary psychiatric disorder, was seen in only $5.4 \%$ of the patients and all of them were of neurotic excoriation in contrast to Quadir et. al. ${ }^{2}$ who reported cases of neurotic excoriation along with trichotillomania and dermatitis artefacta. Psychocutaneous disorder are group of primary psychiatric disorder where patients have intact skin at first, but something starts to appear on the body that lead to secondary skin changes. ${ }^{11}$

\section{CONCLUSION:}

Education regarding maintenance of hygiene is recommended in patient with primary psychiatric diseases and their care taker as infectious skin disorder are more common in them. Not only caretakers this group of patients should have regular dermatological consultation for early diagnosis of their skin disease. Large multicentre study is required to provide more information in this subject.

\section{REFERENCES:}

1. Moftah NH, Kamel AM, Attia HM, El-baz MZ, El-Moty Hala M. Skin diseases in patients with primary psychiatric conditions: a hospital based study. Journal of epidemiology and global health, (2013) 3; 131-138.

2. Qadir A, Butt G, Aamir I, Asad F. Skin disorders in patients with primary psychiatric conditions. Journal of Pakistan Association of Dermatologists, 2015; 25 (4): 282-284. 
3. C. S. Koblenzer. Cutaneous manifestations of psychiatric disease that commonly present to the dermatologist-diagnosis and treatment. Int'l. J Psychiatry in medicne, 1992; 22(1) 47-63.

4. M. Kuruvila, P. Gahalaut, A. Zacharia. A study of skin disorders in patients with primary psychiatric conditions. Indian J Dermatol Venereol Leprol, 2004; 70:292-295.

5. Gupta MA, Gupta AK. Psychodermatology: an update. J AM Acad Dermatol 1996; 34:1030-46.

6. Mookhoek EJ, Van De Kerhof PC, Hovens JE, Brouwers JR, Loonen AJ. Skin disorder in chronic psychiatric illness. J Eur Acad Dermatol Venerol 2010; 24:1151-6.

7. Segerstrom SC, Miller GE. Psychological stress and the human immune system. A meta-analytic study of 30 years of onquiry. Pschol Bull 2004; 130:601-30.

8. Chosidow $O$. scabies and pediculosis. Lancet 2000; 355:818.

9. Mercan S.Kivac Altunay I. Psychodermatolgy: collaboration between psychiatry and dermatology. Turk Psikiyatri Derq 2006; 17:30513.

10. Hays RD, Wells KB, Sherbourne $C D$, Rogers $W$, Spritzer K. Functioning and well being outcomes of patients with depression compared with chronic general medical illness. Arch Gen Psychiatry 1995; 52:11-9.

11. Basta-Juzbašić A1, Bukvić Mokos Z Skin changes in primary psychiatric disorders. Acta Dermatovenerol Croat.2015; 23(2):87-95. 